TP Periodica Polytechnica Chemical Engineering

\author{
62(2), pp. 137-143, 2018 \\ https://doi.org/10.3311/PPch.11132 \\ Creative Commons Attribution (i)
}

RESEARCH ARTICLE

\section{Deswelling of Hydrogels in Aqueous and Polyethylene Glycol Solutions. A New Approach for Drug Delivery Application}

\author{
Nour-Elhouda Angar ${ }^{1 *}$, Djamel Aliouche ${ }^{1}$
}

Received 16 June 2017; accepted after revision 06 October 2017

\begin{abstract}
To enhance the properties of pure poly(acrylamide) hydrogel, diprotic maleic acid co-monomer was included into the reaction mixture during hydrogel synthesis. These hydrogels have been shown important swelling in distilled water and deswelling in acidic solution. In present work, we based on these considerations to study the deswelling behaviour of poly(acrylamide-co-maleic acid) hydrogels in different media (air, polyethylene glycol 200 (PEG200), acidic solution). Hydrogels of poly(acrylamide) and its copolymers with maleic acid were prepared by copolymerization and chemical crosslinking with methylene bisacrylamide. The obtained hydrogels have shown substantial mass swelling in distilled water and shrinking in acidic solution and PEG200. Results showed that the PEG200 was a better solvent for hydrogel deswelling and possibly will be used for gel drying.

The swelling and deswelling kinetics were described by second-ordered and first-ordered models, respectively. BSA desorption in PEG200 was also studied.
\end{abstract}

\section{Keywords}

hydrogel, deswelling, polyethylene glycol, kinetics, protein release

\footnotetext{
${ }^{1}$ Laboratory of Polymers Treatment and Forming, F.S.I.,

M'Hamed Bougara University, Boumerdes 35000, Algeria

${ }^{*}$ Corresponding author, e-mail: nour.king@ymail.com
}

\section{Introduction}

Hydrogels, which are a family relatively recent and important of polymers, have an extensive interest in many domains shown by the increasing number of publications [1, 2]. It can be defined as polymers that capable of absorbing water and biological fluid without changing their forms [3, 4]. Hydrogels with $\mathrm{pH}$ sensitivity character can be swollen from ionic networks that contain either acidic or basic pendant groups as $\left(-\mathrm{COOH},-\mathrm{SO}_{3} \mathrm{H}\right.$ and $-\mathrm{RNH}_{2}$ ), which can accept or release the proton $\left(\mathrm{H}^{+}\right)$depended on the external $\mathrm{pH}[5,6]$. As the changes of surrounding $\mathrm{pH}$, the capacity of water absorbing in $\mathrm{pH}$-sensitive hydrogels is significantly changed at a certain $\mathrm{pH}$ named $\mathrm{pK}_{\mathrm{a}}$ (acid groups) or $\mathrm{pK}_{\mathrm{b}}$ (basic groups) due to the ionization of ionic groups. These ionized groups lead additional swelling of the hydrogel by developing electrostatic repulsions which are influenced not only by $\mathrm{pH}$-medium and also by ionic strength. In this case and when the variations of $\mathrm{pH}$ or ionic strength are not favorable for the swelling, the hydrogel releases its content in water by deswelling to achieve its equilibrium volume $[7,8]$. Thanks to these properties and others, $\mathrm{pH}$-sensitive hydrogels cover today several sectors of application including artificial implants, superabsorbent, chemical and biological sensors, drug delivery and others $[9,10]$.

Other than distilled water, several solvents were proposed to study the swelling of hydrogels, for example, aqueous solutions (physiological saline ( $\mathrm{NaCl} 0.9 \%)$ and saline solutions) and biological fluids (alcohol and buffered solutions). Recently, the swelling behaviour of hydrogels in low molecular weight polymer solutions has been studied. They have shown that hydrogels placed in polyethylene glycol solutions can provoke an irregular mass swelling change. Collapse phenomenon of swollen hydrolyzed poly(acrylamide) hydrogels has observed when these hydrogels are placed in acidic and polyethylene glycol solutions [11]. Based on this valuable character, the main objective of this work is to find a better solvent for hydrogel deswelling and to analyze for the first time the possibility of drug release in liquid polymer by deswelling of hydrogels.

We have chosen the small-chain polyethylene glycol 200 (PEG200), as a deswelling medium of swollen hydrogels. 
Till now, PEG200 which is a liquid polymer is widely used as solvent of some drugs in pharmaceutical applications [12]. Copolymers based on acrylamide and maleic acid at higher ratios of diprotic acid, were prepared by radical cross-linking copolymerization. The copolymers synthesized were characterized through Fourier transform infrared spectroscopy (FT-IR). The swelling behaviour of the obtained hydrogels in water, in acidic solution and in PEG200 was studied. Double ionization of maleic acid at specific $\mathrm{pH}$ offers advantage not only in a great swelling of obtained hydrogels but also in a controlled release performance of immobilized molecules.

For deswelling studies, synthesized hydrogels were placed in distilled water to swell for equilibrium degree and then were removed from this solution and placed in other solution (air, acidic solution, PEG200) to de-swell.

To demonstrate the possibility of drug release by hydrogel deswelling in PEG200, we have performed a preliminary study on the release of bovine serum albumin (BSA) (used as model drugs) from obtained BSA-loaded hydrogels.

\section{Experimental part}

\subsection{Materials}

Acrylamide (AAm) and maleic acid (MA) were supplied by Panreac Chemicals and were used as monomers. N,N'methylene-bis-acrylamide (NbisAAm), potassium persulfate (KPS) and N,N,N',N'-tetramethyl ethylene diamine (TEMED) were supplied by Aldrich Chemical and were used as received.

Polyethylene glycol 200 (PEG200) has an average molecular weight between 190 and $210 \mathrm{~g}^{\mathrm{mol}} \mathrm{mol}^{-1}$ and was used as a solvent for swelling, deswelling and desorption experiments. It was supplied by Panreac Sintesis. Albumin, from bovine serum (BSA) $(\mathrm{Mw}=65 \mathrm{KDa})$ was used as a model protein for adsorption experiments. It was supplied by Aldrich. $\mathrm{NaCl}$ (Panreac) used for salt solutions was used as received.

\subsection{Copolymer hydrogels synthesis}

Hydrogels of AAm and MA were prepared by free radical crosslinking copolymerization procedure in distilled water which is the solvent for all components of the primary mixture. Aqueous solutions of monomers (AAm and MA) and crosslinking agent (NBisAAm) were prepared in $10 \mathrm{~mL}$ of distilled water at different mass percentages of AAm and MA, respectively: $(100,0 \%),(90,10 \%),(80,20 \%)$ and $(70,30 \%)$.

Concentration of the crosslinking agent was typically $1.0 \mathrm{wt} \%$. Amounts of KPS $(0.6 \mathrm{wt} \%)$ and TEMED were added to solution mixture. The solution mixture was prepared under $\mathrm{N}_{2}$ atmosphere. The reaction was kept out for $24 \mathrm{~h}$ in the glass tubes at $25^{\circ} \mathrm{C}$. After the reaction, crosslinked copolymers were cut into portions of about $5 \mathrm{~mm}$ length, then washed continually with distilled water for 3 days and finally dried in a vacuum oven at $35^{\circ} \mathrm{C}$.

The fraction of gel or percentage gelation (G (\%)) was estimated by:

$$
G(\%)=\frac{m_{a}}{m_{b}} \times 100 .
$$

Where, $m_{a}$ and $m_{b}$ are the weights of dry gels after and before extraction respectively.

The G\% values of each sample are presented in Table 1.

Table 1 Summary of EDS of obtained hydrogels

\begin{tabular}{|c|c|c|c|c|}
\hline \multirow{2}{*}{ Samples } & \multicolumn{2}{|c|}{ Mass (\%) } & \multirow{2}{*}{$\mathrm{G}(\%)$} & \multirow{2}{*}{$\begin{array}{l}\text { EDS }(\%) \\
\text { (Distilled water }\end{array}$} \\
\hline & AAm & MA & & \\
\hline MA00 & 100 & 0 & 67.95 & 5013 \\
\hline MA10 & 90 & 10 & 67.71 & 12545 \\
\hline MA20 & 80 & 20 & 63.52 & 16271 \\
\hline MA30 & 70 & 30 & 59.32 & 16283 \\
\hline
\end{tabular}

\subsection{FT-IR characterization}

The functional groups of poly(AAm) and Poly(AAmco-MA) hydrogels were evaluated by Infrared Spectroscopy (FT-IR) in $\mathrm{KBr}$ phase. Dried hydrogels were analyzed in Shimadzu M850 Model, FT-IR Spectrophotometer with 40 scans in the range of $4000-400 \mathrm{~cm}^{-1}$, with a $2 \mathrm{~cm}^{-1}$ resolution.

\subsection{Swelling studies}

The obtained hydrogels were placed in the following liquids distilled water, $\mathrm{pH}=2.2$ and $\mathrm{PEG} 200$, to swell until equilibrium degree at room temperature. The swelling degree, at a time interval $t$, is assessed by weighing the samples after and before immersing in solutions. All the experiments were carried out in triplicate and the average values have been reported in the data. The mass swelling percentage was calculated using the following equation [12]:

$$
S(\%)=\frac{M_{t}-M_{0}}{M_{0}} \times 100 .
$$

Where, $M_{0}$ and $M_{t}$ are the weights of the dry gel at time 0 and the swollen gel at time $t$, respectively.

The equilibrium swelling degrees (EDS (\%)) of hydrogels in distilled water are determined using the following equation:

$$
\operatorname{EDS}(\%)=\frac{M_{e}-M_{0}}{M_{0}} \times 100 .
$$

$M_{e}$ and $M_{0}$ are the mass of swollen gel at equilibrium and mass of dry gel.

\subsection{Deswelling studies}

For the deswelling kinetics measurements, the hydrogels were swollen in distilled water at $25^{\circ} \mathrm{C}$ for equilibrium state and were transferred into PEG200 and into acidic solution $(\mathrm{pH}=1.68)$. Swollen hydrogels are left in the open air to study their deswelling.

The mass changes of hydrogels or water retention were calculated by measuring the mass of each sample at regular times: 


$$
D S=\frac{M_{t}-M_{0}}{M_{e}-M_{t}} .
$$

Where, $M_{e}$ and $M_{t}$ are the weights of the swollen gel at equilibrium time and at time $\mathrm{t}$, respectively.

\subsection{Release of BSA loaded onto hydrogels (in PEG200)}

BSA was incorporated onto obtained hydrogels by swelling of hydrogels in BSA solution in physiological saline $(\mathrm{NaCl}$ $0.9 \%$ ) [13]. For the loading measurements, the dried hydrogels $(0.1 \mathrm{~g})$ were swollen in $2 \mathrm{~g} \mathrm{~L}^{-1}$ saline BSA solution (BSA-NaCl $0.9 \%$ ), at $25^{\circ} \mathrm{C}$ until equilibrium. Amounts of BSA incorporated were determined by the concentration change of BSA in external solution before and after loading at $278 \mathrm{~nm}$ using UV spectrophotometer (UV-1800/SHIMADZU). The total amounts of BSA loaded in hydrogels were investigated in our previous works [14].

The BSA-loaded hydrogels were placed in $20 \mathrm{~mL}$ of PEG200 for BSA-desorption study from hydrogels at room temperature. The amount of BSA desorbed was determined at a regular time by measuring the BSA concentration in PEG200 at $278 \mathrm{~nm}$. At equilibrium state, the value of fraction of BSA released from hydrogel was given by the following formula [15]:

$$
R_{d}(\%)=\frac{m_{e q u}}{m_{\infty}} \times 100 .
$$

Or; $m_{\text {equ }}$ and $m_{\infty}$ are the amount of BSA released at equilibrium state and the amount of BSA incorporated onto hydrogel.

\section{Results and discussions}

\subsection{Copolymer hydrogel synthesis}

Copolymeric hydrogels were prepared with different percentages of acrylamide and maleic acid by free radical copolymerization/crosslinking in aqueous solution using the same amounts of crosslinking agent (NBisAAm) and redox system as initiator (KPS+TEMED).

In Table 1 , the percentage gelation $(\mathrm{G}(\%))$ decreases with increase in the mass percentage of diprotic maleic acid. This decrease in gel fraction can be explicated by the less reactivity ratio of co-monomer (maleic acid) and the effect of $\mathrm{pH}$ during reaction of copolymerization in reactivity of acrylamide. It is apparent from Table 1 that the gel quantity of pure poly(acrylamide) hydrogel is superior to the other copolymers. It is known that the reactivity of acrylamide monomers as well as acidic monomers reacting with acrylamide increase with increasing $\mathrm{pH}[16,17]$. As decreasing $\mathrm{pH}$ with an increase in the mass percentage of diprotic acid during copolymerization procedure of acrylamide monomers, the quantity of gel formed decreases.

From literature, the amide function of acrylamide monomers has a great affinity and compatibility with carboxylic groups (maleic acid). Therefore, the gel based on acrylamide and maleic acid is obtained and decreases with increase in the amount of diprotic maleic acid [18].
Fig. 1 shows the Infrared spectra of poly(AAm) and its copolymers with maleic acid. By comparing FTIR spectra of investigated copolymers, it is clear that the characteristic absorption peaks of poly(acrylamide) and its copolymers with diprotic acid are present (Table 2); between $3420-3475 \mathrm{~cm}^{-1}$ (broad) : indicating the N-H stretching of $\left(\mathrm{CONH}_{2}\right)$; between $1650-1700 \mathrm{~cm}^{-1}$ : indicating the $\mathrm{C}=\mathrm{O}$ stretching of $\left(\mathrm{CONH}_{2}\right)$; between 1686$1740 \mathrm{~cm}^{-1}$ : indicating the $\mathrm{C}=\mathrm{O}$ stretching of $(\mathrm{COOH})$ (recovered by $\mathrm{C}=\mathrm{O}$ of amide) ; between $1400-1567 \mathrm{~cm}^{-1}$ : indicating the $(\mathrm{C}-\mathrm{O})$ stretching of $\left(\mathrm{COO}^{-}\right)$of the $(-\mathrm{COOH})$ groups $[19,20]$.

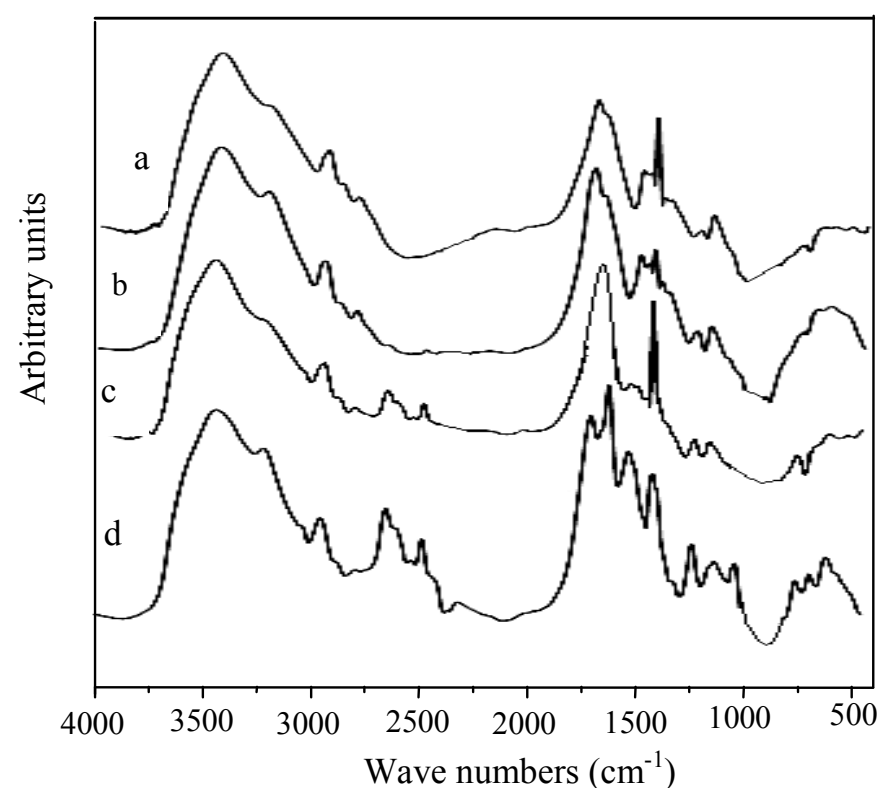

Fig. 1 FT-IR spectra of the poly(AAm) (a) and poly(AAm-co-MA) hydrogel samples, with $10 \%$ (b), $20 \%$ (c) and $30 \%$ (d) MA respectively.

Table 2 The assigment of obtained FTIR bands.

\begin{tabular}{llll}
\hline \multicolumn{2}{c}{ Peak $\left(\mathrm{cm}^{-1}\right)$} & Assignment & Reference \\
\cline { 1 - 3 } This work & In reference & & \\
\hline $3420-3475$ & 3456 & $\mathrm{~N}-\mathrm{H}\left(\mathrm{CONH}_{2}\right)$ & {$[21]$} \\
$1650-1700$ & $1650-1660$ & $\mathrm{C}=\mathrm{O}\left(\mathrm{CONH}_{2}\right)$ & {$[19]$} \\
$1686-1740$ & 1716 & $\mathrm{C}=\mathrm{O}(\mathrm{COOH})$ & {$[19]$} \\
$1400-1567$ & 1400 & $(\mathrm{C}-\mathrm{O})(\mathrm{COO})$ & {$[22]$} \\
\hline
\end{tabular}

\subsection{Behaviours and Kinetics of swelling}

The equilibrium swelling (EDS (\%)) of poly(AAm) and its copolymer hydrogels in distilled water is illustrated in Table 1. In this table, the EDS values of copolymer hydrogels are higher than the EDS of pure poly(acrylamide). The hydrophilicity of copolymer hydrogels is ensured by the carboxylic groups attached to amide functions of acrylamide.

In this case, the swelling occurs through electrostatic repulsion between anions present within the network and by the polymer elasticity [23, 24].

Copolymer hydrogel with higher acid content (MA30) has a higher concentration of anionic groups providing a higher degree of swelling. 
The swelling curves of poly(AAm-co-MA) hydrogels in acidic solution $(\mathrm{pH}=2.2)$ and PEG200 are shown in Fig. 2 and Fig. 3 respectively. The samples are placed in acidic buffered solution $(\mathrm{pH}=2.2)$ at room conditions $\left(22^{\circ} \mathrm{C}\right)$ and we followed their swelling as a function of time (Fig. 2).

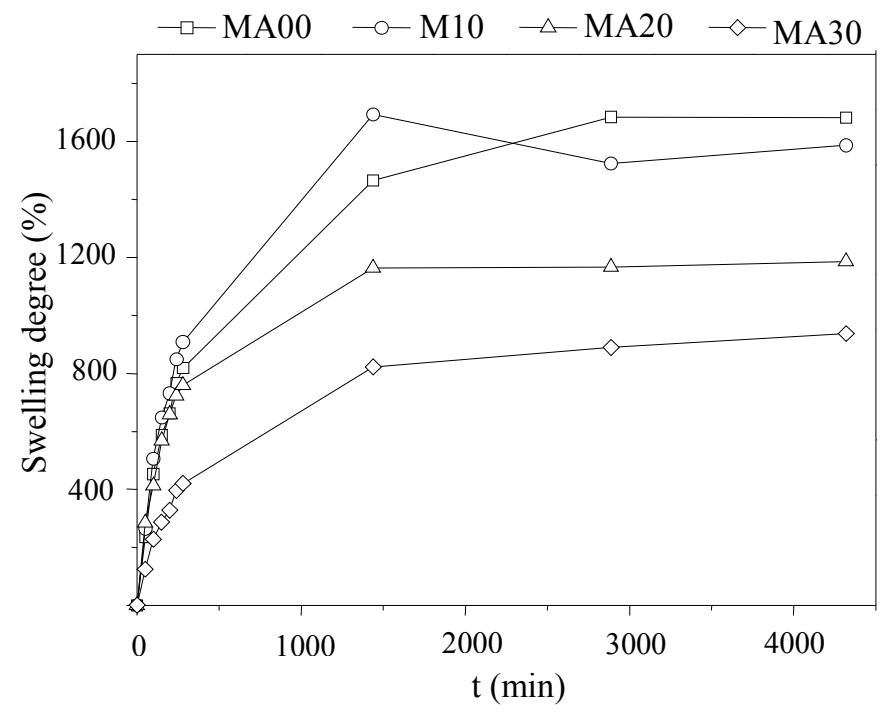

Fig. 2 Swelling kinetics of hydrogels in acidic solution $(\mathrm{pH}=2.2)$.

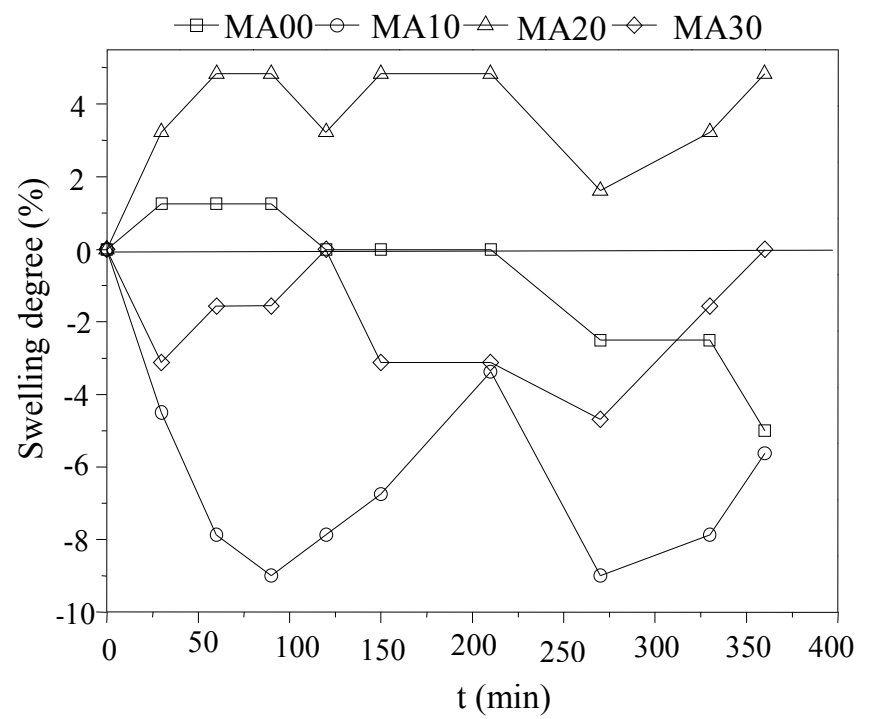

Fig. 3 Swelling kinetics of copolymer hydrogels in PEG200

In Fig. 2, in equilibrium state the swelling of copolymers (MA10, MA20 and MA30) under acidic pH is lower than MA00. The change of swelling degree with time (swelling rate) of all samples is not significant. At low $\mathrm{pH}$ values, the carboxylic groups in the side chains were not ionized and intermolecular complexation via $\mathrm{H}$-bonds occurred between - $\mathrm{COOH}$ of the MA and $-\mathrm{CONH}_{2}$ of the AAm units in the hydrogel (physical crosslinking). This interaction increases with increasing of acid content. It is known that the dissociation of the acid groups arises once the $\mathrm{pH}$ of the external medium is above the characteristic $\mathrm{pKa}$ of acid. The first and second ionization constants of $\mathrm{MA}$ are $\mathrm{pKa}_{1}=1.89$ and $\mathrm{pKa}_{2}=6.23$ respectively. At acidic
$\mathrm{pH}(<6.23)$, carboxylic acid groups are protonated and exhibit hydrophobic character, leading less absorption of water into the polymer. When $\mathrm{pH}$ value of external solution is very acidic $(\mathrm{pH}=2.2)$ the swelling degree decreases with the concentration of diprotic acid (MA00, MA10, MA20 and MA30), in the following order: $\mathbf{S}_{\mathrm{MA00}}>\mathbf{S}_{\mathrm{MA10}}>\mathbf{S}_{\mathrm{MA} 20}>\mathbf{S}_{\mathrm{MA} 30}$.

In PEG200, the swelling is not important, because all samples show perturbation changes in their swelling degree. It is shown in Fig. 3.

It is clear from Fig. 3 that there is no swelling in PEG200. The swelling degree decreases with times in negative values. This behavior may be explained by the importance of osmotic pressure created by the high concentration of PEG200 in the system. The water inside hydrogel network diffuses to the external medium to achieve the equilibrium state of system. These results show that PEG can be used as a deswelling solvent for swollen hydrogels.

The kinetic swellings of these hydrogels are modulated by using second-order kinetic equation [16]:

$$
\frac{d S(t)}{d t}=K_{s}\left(S_{\max }-S_{t}\right)^{2}
$$

By integration of this equation on the initial conditions $\left(S=0\right.$ at $t=0$ and $S=S_{t}$ at $\left.t=t\right)$, it was found:

$$
\frac{t}{S_{t}}=\frac{1}{S_{\max }} \times t+\frac{1}{K_{S} \cdot S_{\max }^{2}} .
$$

Where; $S_{t}$ is the swelling degree at time t, $S_{\max }$ is the maximum or equilibrium swelling degree and $K_{S}$ is the second order swelling constant.

The results are shown in Table 3 .

Table 3 Kinetic paramaters of swelling for obtained hydrogels.

\begin{tabular}{lllllll}
\hline & \multicolumn{3}{c}{ Distilled water } & \multicolumn{3}{c}{$\mathrm{pH}=2.2$} \\
\cline { 2 - 7 } & $\mathrm{S}_{\max }(\%)$ & $\mathrm{K}_{\mathrm{s}} \cdot 10^{5}$ & $\mathrm{R}^{2}$ & $\mathrm{~S}_{\max }(\%)$ & $\mathrm{K}_{\mathrm{s}} \cdot 10^{5}$ & $\mathrm{R}^{2}$ \\
\hline MA00 & 5814.9 & 2.48 & 0.99 & 1763.6 & 18.19 & 0.99 \\
MA10 & 17857.1 & 0.30 & 0.99 & 1730.1 & 24.95 & 0.99 \\
MA20 & 23256.8 & 0.24 & 0.98 & 1225.4 & 49.91 & 0.99 \\
MA30 & 30303 & 0.09 & 0.99 & 1055.9 & 23.52 & 0.99 \\
\hline
\end{tabular}

The values of constants $K_{S}$ and $S_{\max }$ can be calculated using the equations of liners obtained. Where $\left(1 / K_{S} \cdot S_{\text {max }}^{2}\right)$ is the value of interaction lines (with y) and $K_{S}$ are calculated using slopes and obtained $S_{\max }$ (Table 3).

In distilled water, the incorporation of diprotic acid in poly(AAm) hydrogel increases the equilibrium degree of swelling $\left(\mathrm{S}_{\max } \%\right)$ and decreases the values of swelling constants $\left(K_{s}\right)$. So, when the hydrophilicity of network increases, the constant of swelling decreases (Table 3), the values of theoretical equilibrium degree of swelling $\left(S_{\max } \%\right)$ of the samples are comparable to the experimental values $\operatorname{EDS}(\%)$. 
The kinetic reserve is observed in acidic $\mathrm{pH}$ solution $(\mathrm{pH}=2.2)$. When the content of maleic acid in hydrogels is augmented the equilibrium swelling degree $\left(\mathrm{S}_{\max } \%\right)$ decreases and the swelling constant $\left(\mathrm{K}_{\mathrm{s}}\right)$ increases. Pendant groups of poly(AAm-co-MA) hydrogel are un-ionized in $\mathrm{pH}=2.2$ leading the formation of hydrogen bonding between acrylamide and maleic acid (hydrophobic character). So, the equilibrium swelling $\left(\mathrm{S}_{\max } \%\right)$ is low for all samples and decreases with the concentration of MA.

\subsection{Deswelling kinetics}

Figures 4, 5 and 6 show the deswelling curves of poly(AAmco-MA) hydrogels with different MA content in acidic solution, in PEG200 and in air, respectively.

According to Fig. 4, the deswelling rate of pure poly(AAm) and its copolymer with a low content of maleic acid (MA10) hydrogels is very slow (almost unchanged with time). By contrast, the deswelling rate of other copolymers (MA20 and MA30) is rapid and varies from 1 to 0.4 .

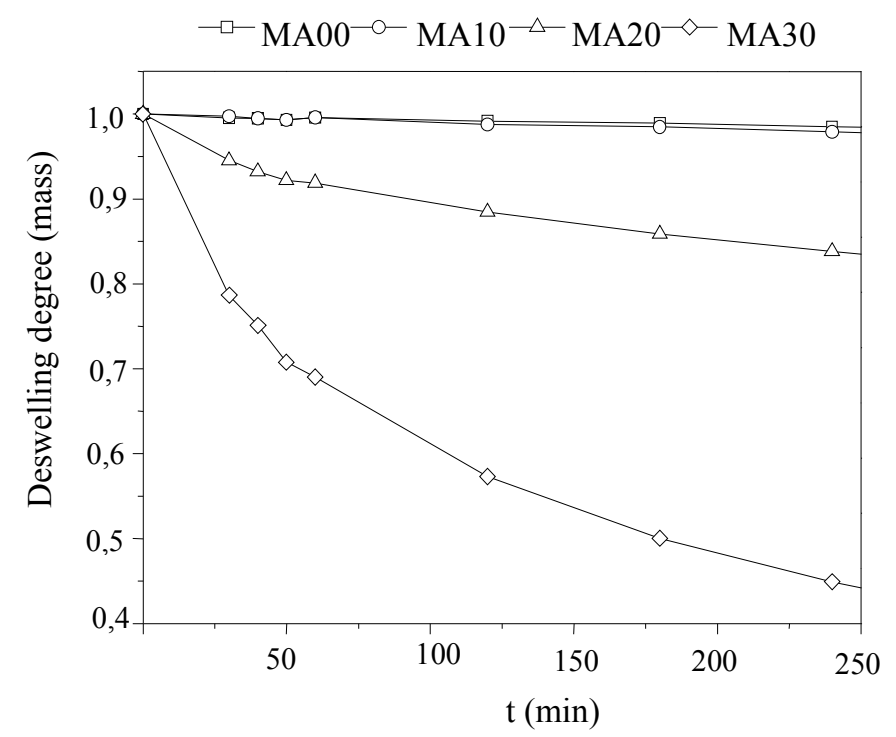

Fig. 4 Deswelling kinetics of copolymer hydrogels in $\mathrm{pH}=1.68$.

The deswelling of MA00 and MA10 hydrogels is not significant $\mathrm{pH}$ dependence $(\mathrm{pH}=1.68)$. It is well known that while poly(AAm) does not respond to changes in $\mathrm{pH}$ buffer solutions, poly(AAm-co-MA) is a typical pH-sensitive copolymer that can deprotonate its carboxyl moieties in alkaline solution and protonate them in acidic solution. Consequently, the $\mathrm{pH}$-responsive nature of copolymer hydrogels is enhanced by increasing the amount of MA. Thus, the concentration of carboxylic functions within hydrogel facilitates the diffusion of water molecules to the external medium. This behaviour at acidic solution makes the copolymer system to be highly $\mathrm{pH}$-responsive and consequently it may be a suitable candidate for designing controlled drug delivery systems. Similar results have been reported by other hydrogel systems [25, 26].
It is clearly seen from Fig. 5 that the deswelling degree or water retention decreases with increase in the MA content. It is shown that $100 \mathrm{~min}$ is sufficient to lose more than $80 \%$ of water. Deswelling degree of copolymers decreases until equilibrium value inferior to that of pure poly(AAm) hydrogel. The main remark is the faster deswelling of all hydrogels in PEG200.

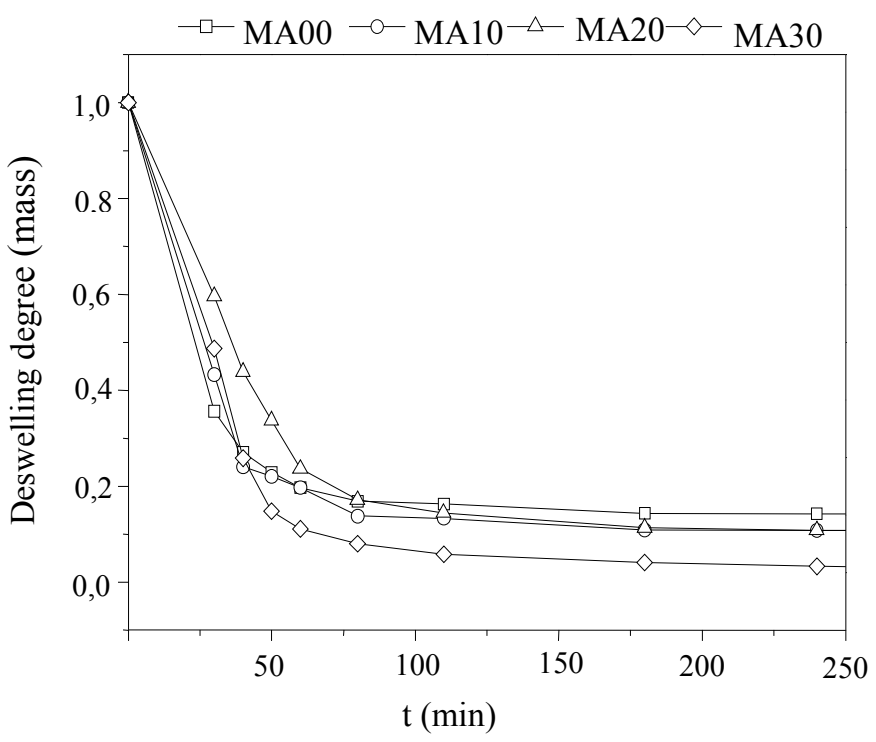

Fig. 5 Deswelling kinetics of copolymer hydrogels in PEG200.

As seen from Fig. 6, the water retention of all hydrogels is significant compared to this in PEG200. The non-ionic poly(AAm) hydrogel tends to deswell quickly compared to the copolymers and loses water content within time of $200 \mathrm{~min}$. The reason for this is that MA monomers containing hydrophilic carboxylic groups bind water molecules via strong hydrogen bonds which it is difficult for water molecules to flee from hydrogels [27, 28].

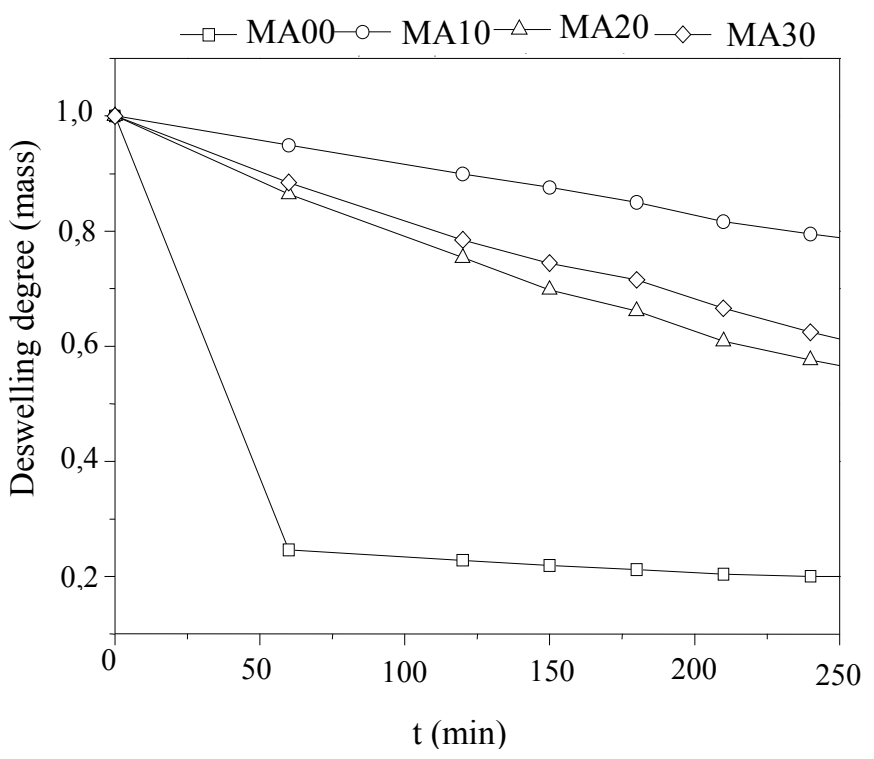

Fig. 6 Deswelling kinetics of copolymer hydrogels in air. 


\subsection{Release of BSA loaded onto hydrogels}

BSA adsorption onto hydrogels mainly depends on the swelling behavior of the hydrogel; higher swelling degree suggests larger amount of BSA adsorbed. The total amounts of BSA loaded in hydrogels were investigated in our previous works [14]. In this study, we analyze for the first time the possibility of BSA release in liquid polymer by deswelling of hydrogels. The hydrogels are initially kept in BSA solution and allowed to swell to their equilibrium value. Later, the swollen hydrogels are taken out and placed in PEG200 until equilibrium is reached. The values of BSA desorbed fraction were calculated using Eq. (5) and results are injected in Table 4.

Table 4 The values of BSA desorbed fraction in PEG200.

\begin{tabular}{lll}
\hline Samples & $\mathrm{m}_{\text {equ }}(\mathrm{mg}(\mathrm{BSA}) / \mathrm{g}$ polymer $)$ & $\mathrm{R}_{\mathrm{d}}(\%)$ \\
\hline MA00 & 37.71 & 97.99 \\
MA10 & 54.41 & 32.71 \\
MA20 & 53.76 & 25.55 \\
MA30 & 42.06 & 18.14 \\
\hline
\end{tabular}

From this result, the release of BSA in PEG200 can be achieved because all the present values of $R_{d}$ are significant. This last one decreases with an increase in the amount of MA monomer. This decrease is due to the particular interactions between carboxyl groups and BSA molecules. These interactions increase with an increase in the MA content, initiating a decrease in the hydrogel desorption capacity.

\section{Conclusion}

Hydrogels of poly(acrylamide) and its copolymers with diprotic maleic acid were prepared by copolymerization and chemical crosslinking with methylene bis-acrylamide. The swelling and deswelling kinetics of these hydrogels in water, acidic solution and PEG were investigated. The second-ordered swelling and the first-ordered deswelling kinetics were demonstrated for all hydrogels. Poly(acrylamide) and its copolymer hydrogels collapsed in PEG200, in acidic solution and in air. The deswelling kinetics of pH-sensitive hydrogels in PEG200 is much faster than that in air. It is shown that PEG can be used as a dehydrating solvent for hydrogels. Hydrogels in PEG200 and at the time of $100 \mathrm{~min}$ lost more than $80 \%$ of water content. It is concluded that PEG is an important deswelling solvent and can be used for drug release applications.

\section{References}

[1] Gaharwar, A. K., Peppas, N. A., Khademhosseini, A. "Nanocomposite hydrogels for biomedical applications." Biotechnology and Bioengineering. 111(3), pp. 441-453. 2014.

https://doi.org/10.1002/bit.25160

[2] Lee, S. Ch., Kwon, I. K., Park, K. "Hydrogels for delivery of bioactive agents: A historical perspective." Advanced Drug Delivery Reviews. 65(1), pp. 822-832. 2013. https://doi.org/10.1016/j.addr.2012.07.015
[3] Patel, A., Mequanint, K. "Hydrogel Biomaterials." In: Fazel-Rezai, R. (ed.) Biomedical Engineering - Frontiers and Challenges. (pp. 276296.), Chapter 14, InTech, 2011.

https://doi.org/10.5772/24856

[4] Laftah, W. A., Hashim, S., Ibrahim, A. N. "Polymer Hydrogels: A Review." Polymer-Plastics Technology and Engineering. 50(14), pp. 1475 1486. 2011.

https://doi.org/10.1080/03602559.2011.593082

[5] Peppas, N. A., Bures, P., Leobandung, W., Ichikawa, H. "Hydrogels in pharmaceutical formulations." European Journal of Pharmaceutics and biopharmaceutics. 50(1), pp. 27-46. 2000.

https://doi.org/10.1016/S0939-6411(00)00090-4

[6] Hoffman, A. S. "Intelligent polymers in medicine and biotechnology." Macromolecular Symposia. 98(1), pp. 645-664, 1995.

https://doi.org/10.1002/masy.19950980156

[7] Pal, K.., Banthia, A. K., Majumdar, D. K. "Polymeric Hydrogels: Characterization and Biomedical Applications -A mini review." Designed Monomers and Polymers. 12(3), pp. 197-220. 2009.

https://doi.org/10.1163/156855509X436030

[8] Qiu, Y., Park, K. "Environment-sensitive hydrogels for drug delivery." Advanced Drug Delivery Reviews. 53(3), pp. 321-339. 2001.

https://doi.org/10.1016/S0169-409X(01)00203-4

[9] Koetting, M. C., Peters, J. T., Steichen, S. D., Peppas, N. A. "Stimulus-responsive hydrogels: Theory, modern advances, and applications." Materials Science and Engineering: R: Reports. 93, pp. 1-49. 2015. https://doi.org/10.1016/j.mser.2015.04.001

[10] Richter, A., Paschew, G., Klatt, S., Lienig, J., Arndt, K.-F., Adler, H.-J. P. "Review on Hydrogel-based pH Sensors and Microsensors." Sensors. 8(1), pp. 561-581. 2008.

https://doi.org/10.3390/s8010561

[11] Kayaman, N., Okay, O., Baysal, B. M. "Swelling of polyacrylamide gels in aqueous solutions of ethylene glycol oligomers." Polymer Gels and Networks. 5(4), pp. 339-356. 1997.

https://doi.org/10.1016/S0966-7822(97)00005-1

[12] Milton, H. J. "Poly(Ethylene Glycol) Chemistry Biotechnical and Biomedical Applications." Springer Science+Business Media, New York. 1992.

[13] Saraydin, D., Karadag, E., Guven, O. "Acrylamide/maleic acid hydrogels." Polymers for Advanced Technologies. 6(12), pp. 719-726. 1995. https://doi.org/10.1002/pat.1995.220061201

[14] Angar, N. E., Aliouche, D. "An enhanced immobilization of BSA biomolecule on anionic hydrogels: swelling and adsorption modelling." Chemical Papers. 71(8), pp. 1389-1397. 2017.

https://doi.org/10.1007/s11696-017-0129-4

[15] Öztop, H. N., Saraydın, D., Şolpan, D., Güven, O. "Adsorption of BSA onto radiation-crosslinked poly (AAdHPMAMA) terpolymers." Polymer Bulletin. 50(3), pp. 183-190. 2003.

https://doi.org/10.1007/s00289-003-0152-1

[16] He, J., Ni, P., Wang, S., Shao, H., Zhang, M., Zhu, X. "Synthesis and Physicochemical Characterization of Biodegradable and $\mathrm{pH}$-Responsive Hydrogels Based on Polyphosphoester for Protein Delivery." Journal of Polymer Science Part A: Polymer Chemistry. 48(9), pp. 1919-1930. 2010. https://doi.org/10.1002/pola.23959

[17] Cabaness, W. R., Lin, T. Y. C., Parkanyi, C. "Effect of pH on the reactivity ratios in the copolymerization of acrylic acid and acrylamide." Journal of Polymer Science Part A-1: Polymer Chemistry. 9(8), pp. 2155-2170. 1971.

https://doi.org/10.1002/pol.1971.150090805

[18] Klein, J., Hietzmann, R. "Preparation and characterization of poly(acrylamide-co-acrylic acid)." Macromolecular Chemistry and Physics. 179(8), pp. 1895-1904. 1978.

https://doi.org/10.1002/macp.1978.021790803 
[19] Kaşgöza, H., Aydınb, İ., Kaşgöza, A. "The effect of PEG(400)DA crosslinking agent on swelling behaviour of acrylamide-maleic acid hydrogels." Polymer Bulletin. 54(6), pp. 387-397. 2005.

https://doi.org/10.1007/s00289-005-0408-z

[20] Karadağ, E., Saraydın, D., Güven, O. "Radiation induced superabsorbent hydrogels. Acrylamide/itaconic acid copolymers." Macromolecular Materials and Engineering. 286(1), pp. 34-42. 2001.

https://doi.org/10.1002/1439-2054(20010101)286:1<34::AID-MAME34>3.0.CO;2-J

[21] Popa, N., Novac, O., Profire, L., Hritcu, D., Popa, M. I. "Inclusion and release of theophylline from chitosan based microparticles." Turkish Journal of Chemistry. 34(2), pp. 255-262. 2010. https://doi.org/10.3906/kim-0812-29

[22] Krušić, M. K., Džunuzović, E., Trifunović, S., Filipović, J. "Polyacrylamide and poly(itaconic acid) complexes." European Polymer Journal. 40(4), pp. 793-798. 2004.

https://doi.org/10.1016/j.eurpolymj.2003.11.016

[23] Mahdavinia, G. R., Pourjavadi, A., Hosseinzadeh, H., Zohuriaan, M. J. "Modified chitosan 4. Superabsorbent hydrogels from poly(acrylic acid-co-acrylamide) grafted chitosan with salt-and pHresponsiveness properties." European Polymer Journal. 40(7), pp. 1399-1407. 2004. https://doi.org/10.1016/j.eurpolymj.2004.01.039

[24] Mahdavinia, G. R., Massoumi, B., Jalili, K., Kiani, G. "Effect of sodium montmorillonite nanoclay on the water absorbency and cationic dye removal of carrageenan-based nanocomposite superabsorbents." Journal of Polymer Research. 19(9), pp. 1-13. 2012.

https://doi.org/10.1007/s10965-012-9947-9
[25] Elliott, J. E., Macdonald, M., Nie, J., Bowman, C. N. "Structure and swelling of poly (acrylic acid) hydrogels: effect of $\mathrm{pH}$, ionic strength, and dilution on the crosslinked polymer structure." Polymer. 45(5), pp. 1503-1510. 2004.

https://doi.org/10.1016/j.polymer.2003.12.040

[26] Kim, B., La Flamme, K., Peppas, N. A. "Dynamic swelling behavior of $\mathrm{pH}$-sensitive anionic hydrogels used for protein delivery." Journal of Applied Polymer Science. 89(6), pp. 1606-1613. 2003.

https://doi.org/10.1002/app.12337

[27] Katime, I., Mendizábal, E. "Swelling Properties of New Hydrogels Based on the Dimethyl Amino Ethyl Acrylate Methyl Chloride Quaternary Salt with Acrylic Acid and 2-Methylene Butane-1,4-Dioic Acid Monomers in Aqueous Solutions." Materials Sciences and Applications. 1(03), pp. 162-167. 2010.

https://doi.org/10.4236/msa.2010.13026

[28] Liu, Y., Cui, Y., Wu, G., Liao, M. "Preparation and properties of fast temperature-responsive soy protein/PNIPAAm IPN hydrogels." Journal of the Serbian Chemical Society. 79(2), pp. 211-224. 2014. https://doi.org/10.2298/JSC130219047L 